\title{
Uma teia invisível de relações
}

\section{Tiago Bartolomeu Costa}
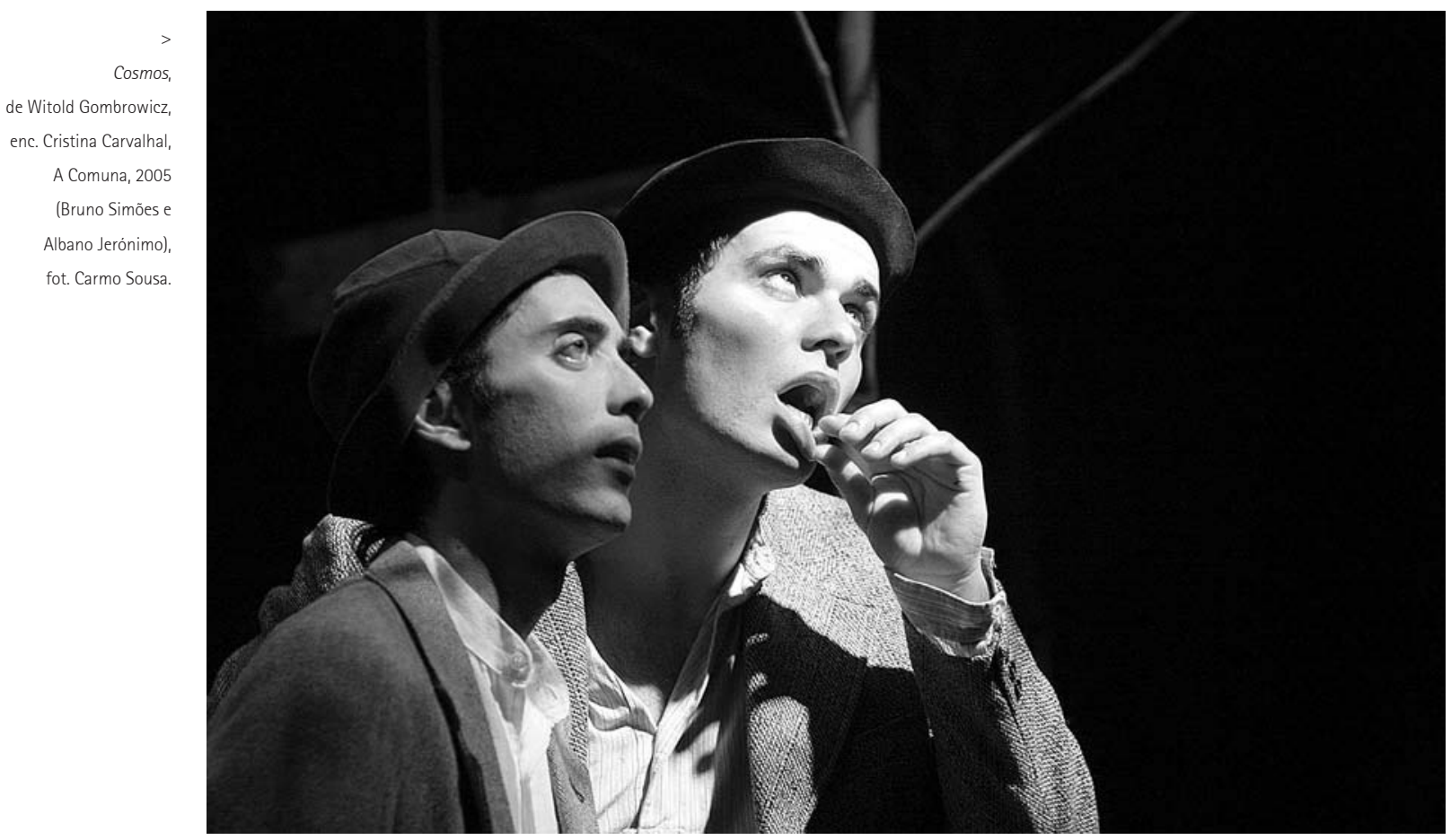

Titulo: Cosmos (1967). Autor:Witold Gombrowicz. Encenação: Cristina Carvalhal. Adaptação dramatúrgica (a partir da tradução de Luiza Neto Jorge): Cristina Carvalhal. Direcção plástica: Ana Limpinho e Maria João Castelo. Música: Sérgio Delgado. Desenho de luz: João Paulo Xavier. Apoio ao movimento: Jens Altheimer. Produção: Mafalda Gouveia. Interpretação: Albano Jerónimo, André Levy, Bruno Simões, Cucha Carvalheiro, Luis Gaspar, Manuela Couto e Sandra Faleiro. Local e data de estreia:Teatro A Comuna, Lisboa, 10 de Março de 2005.

Cosmos é a adaptação dramatúrgica, por Cristina Carvalhal (também encenadora), do romance homónimo de Witold Gombrowicz, vencedor do Prémio Internacional da Literatura 1967. Com traços de romance policial, "conta" a história de Witold (Albano Jerónimo), jovem estudante, que se faz acompanhar de um amigo, Fuchs (Bruno Simões), numas férias em lugar e data incertos. Os dois entram numa floresta e encontram um pássaro enforcado. Este elemento estranho é o ponto de partida para uma investigação sobre o poder das acções, o controlo sobre as mesmas e as implicações de determinados comportamentos. Witold e Fuchs alojam-se numa pensão familiar (dos Wojtis). A matriarca, Wojtis
Bouboule (Cucha Carvalheiro) é mulher austera mas com imprevisiveis crises de nervos; o marido, Leon (André Levy), é figura de senso comum, com um discurso repartido entre metáforas, jogos de palavras e puras banalidades; a filha do casal, Lena (Sandra Faleiro), é rapariga entre o frágil e o arrogante, casada com Lucien (Luis Gaspar), um homem racional, incapaz de responder aos apelos sexuais da mulher e em confronto com o discurso pobre do sogro. Na pensão habita ainda Catherette (Manuela Couto), sobrinha dos donos, com uma cicatriz na cara (efeito de um acidente de carro), mas mulher a desejar ser inteira (são várias as sugestões, todas elas visuais, de um desejo de gravidez e parto). A história é-nos narrada de forma a que possa ser interpretada como uma ambiguidade temporal. Witold entra em cena anunciando que já é tarde para contar essa história. E nesta hesitação reside a primeira dúvida de Cosmos: trata-se da reconstrução de uma memória, ou antes uma narração dos factos que ocorrem no presente? 0 que quer que seja é suficiente para envolver o espectador num jogo de mistério e suspense que, mais do que mostrar, antes procura pensar determinados comportamentos tendentes a sustentar um certo nivel de racionalidade nas coisas do mundo'.

Esta primeira dúvida cruza uma ideia de teatro (sugerindo nomeadamente os prólogos clássicos) com a intenção de Gombrowicz de fazer de Cosmos um policial sobre a busca da forma e da anulação do caos. E assim remete o espectáculo para uma proposta dramatúrgica híbrida, não só pela dificuldade de classificação genológica (à qual não é alheia toda uma reflexão/intenção artística 

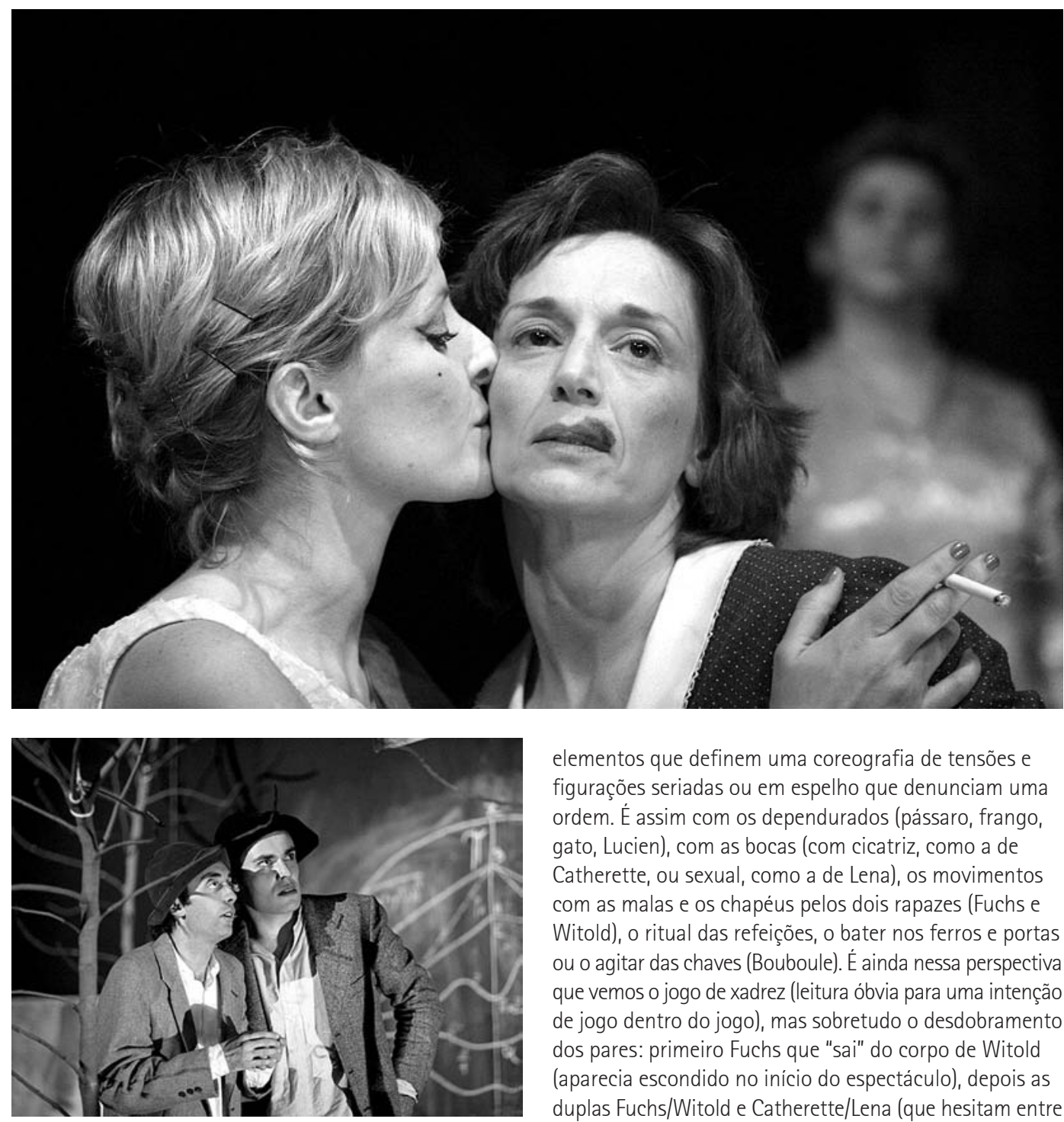

de forte impacto visual), mas também pela impossibilidade de dar a ver uma solução para um objecto que se quer parte de um todo: o próprio cosmos.

Diria que Cosmos cruza três planos: o real, o onírico e o da narrativa. Estes três níveis de leitura, apresentados numa estrutura fragmentada e numa multiplicidade de acções, desenvolvem-se a partir de duas linhas de força, que não só se reportam às teorias de Gombrowicz acerca da luta entre a "forma" e o homem, como permitem organizar o olhar do espectáculo sob um prisma menos caótico e perturbador. A primeira dessas linhas é algo a que podemos chamar "dentro da forma": nela encontramos elementos que definem uma coreografia de tensões e figurações seriadas ou em espelho que denunciam uma ordem. É assim com os dependurados (pássaro, frango, gato, Lucien), com as bocas (com cicatriz, como a de Catherette, ou sexual, como a de Lena), os movimentos com as malas e os chapéus pelos dois rapazes (Fuchs e Witold), o ritual das refeições, o bater nos ferros e portas ou o agitar das chaves (Bouboule). É ainda nessa perspectiva que vemos o jogo de xadrez (leitura óbvia para uma intenção de jogo dentro do jogo), mas sobretudo o desdobramento dos pares: primeiro Fuchs que "sai" do corpo de Witold (aparecia escondido no início do espectáculo), depois as duplas Fuchs/Witold e Catherette/Lena (que hesitam entre Lucien e Lena que carregam duas marionetas, cópias assustadoras das suas figuras, que oscilam entre projecções das suas fantasias sexuais e um casal amigo que parece recusar a forma. Estes jogos de pares permitem interpretar Cosmos como uma fina e delicada teia invisivel de relações que, mais do que construirem uma rede que sustente a veracidade da história, antes preferem enredar-se (/-nos) em enganos, ambiguidades, segredos e mistérios. Razão pela qual o número de personagens (se descontarmos a personagem-público) é impar: há uma personagem de fora, que tudo vê e tudo sabe. Podia ser Catherette, mas é Lucien que morre. o sonho e a realidade) e depois, já na viagem para a floresta,
Cosmos,

de Witold Gombrowicz, enc. Cristina Carvalhal, A Comuna, 2005 (Sandra Faleiro, Manuela Couto e Cucha Carvalheiro), fot. Carmo Sousa.

Cosmos, de Witold Gombrowicz, enc. Cristina Carvalhal, A Comuna, 2005 (Bruno Simões e Albano Jerónimo) fot. Carmo Sousa 
A outra linha é, obviamente, "fora da norma". Na profusão (muito variada) de adereços cénicos encontramos elementos simbólicos como um gato que oscila entre objecto de decoração, reduto de prazer e sugestão de animal, jarros que deitam folhas, flores que caem do céu, morangos presos às pontas das árvores (tão vermelhas como os lábios das mulheres e os rabanetes na mesa - o vermelho como ideia medieval de pecado e morte?), peixes presos a um fio, paus suspensos, fórmulas matemáticas nas paredes, chaves maiores do que a fechadura, árvores sem raizes, portas sem paredes, uma escada que não conduz a lado nenhum e, sobretudo, uma floresta que invade a casa e a plateia. Pela sua estranheza, podemos interrogar para que servem estes objectos?

A verdade é que Cosmos se desenvolve a partir de uma simbologia que quase podíamos dizer exacerbada, sugerindo um caos a necessitar de ser organizado. E o papel do espectador é, então, essencial, uma vez que terá a oportunidade de seleccionar o que de mais relevante exista para encontrar a ordem, funcionando como um detective que procura identificar não quem fez, mas porque fez. Por isso, Cosmos é menos whodunit e mais whyhedidit.

0 espectáculo, nesse aspecto, não é original, nem pela sua forma nem pelo seu conteúdo. Afinal, espectáculos que começam com a intenção de narrar uma história existem desde que o teatro foi inventado. $E_{1}$ melhor ou pior, todos os dramatugos já experimentaram essa técnica de fazer o espectador crer que aquilo a que está a assistir é uma reconstituição de um facto e não a construção de uma realidade presente. Mas Cosmos, como qualquer policial, expõe as pistas de tal forma que obriga o espectador a questionar o seu lugar enquanto parte da acção (ou da decisão).

É, por isso, uma generalidade dizer-se que um espectáculo é "um pretexto para uma investigação sobre as convenções teatrais" (como diz a nota de imprensa), uma vez que todos os espectáculos questionam as convenções teatrais, sendo que uns se permitem ultrapassálas, outros renová-las e outros ainda ficarem presos à inerente efemeridade teatral. Cosmos faz parte do segundo grupo, os que as renovam. Não tanto por aquilo que diz de novo, mas antes por se permitir ser um espectáculoconvocatória de outras memórias, afectividades, relações e analogias, sem fazer da referência um chavão e sem impor leituras.

Há quem vá recordar Ȧ espera de Godot (na entrada dos estudantes, com subtis sinais de Vladimir, Estragon e Lucky, ou no manuseio da corda), quem se lembre da Classe morta, de Kantor (sobretudo pelos manequins/duplos de Lena e Lucien no caminho para a floresta), ou ainda quem pense em Kafka (pelo labirinto de emoções). Eu gostaria de lembrar o Jardim zoológico de cristal, de Tennessee Williams (obviamente pelo defeito de Catherette, mas também pela figura da matriarca dominadora). E Alfred Hitchcock (Vertigo, sobretudo), Fellini (Amarcord e Satyricon), Kusturica (o de Underground), Lars von Trier e o seu alinhamento com Brecht (Dogville), Boris Vian (com o livro Irei cuspir-vos nos túmulos) e todo um conjunto de referências ao imaginário do surrealismo ou à fantasia bucólica, Irmãos Grimm incluidos (naturalmente por causa da floresta negra da Branca de Neve, menos doce que a de Walt Disney). Esta multiplicidade de referentes possíveis, sobretudo ligados ao cinema, dão conta da vontade de ultrapassagem das convenções do teatro, com criação de paisagens oníricas, embora uma leitura mais profunda dos objectos possa revelar uma certa fragilidade na sua significação, nem sempre coincidente com as intenções delineadas.

Se pensarmos na origem do espectáculo Cosmos, devemos considerar que não é dispicienda a sua integração num espaço como o teatro A Comuna, uma vez que são aqui reconheciveis determinadas linhas, não só de criação, como de produção, que geralmente associamos à companhia dirigida por João Mota. É o caso, na criação, de um trabalho dramatúrgico feito a partir da importância da palavra como matéria semiótica, no que isso significa de investigação sobre os efeitos dessa mesma palavra no corpo dos actores, logo, na fisicalidade das personagens. Mas também a economia de elementos cenográficos que, mais do que identificar e fixar imagens, antes procura sugerir linhas de leitura. Podemos ainda considerar a forma como isso se relaciona com as condições de produção, seja pela constituição do elenco, composto por afinidades e empatias pessoais, ou pela forma como procuram contrariar a efemeridade dos espectáculos, nomeadamente com um sítio na internet (com mais informações do que o programa), a venda do livro traduzido por Luíza Neto Jorge e a organização de leituras e debates a partir da obra e do autor. Todos estes aspectos apontam o objecto teatral como um passo num percurso de reflexão artística e não tanto como um objecto acabado. Mas também obrigam a estrutura A Comuna a pensar a forma como se quer relacionar com os projectos pontuais e ainda contribuir para um estudo dos seus trabalhos, sobretudo, por exemplo, ao fazer programas que sejam dignos do percurso da companhia ou da qualidade dos espectáculos. 